\title{
Implications of cascading effects for the EU Floods Directive
}

\author{
Nones Michael ${ }^{1}$, Pescaroli Gianluca ${ }^{2}$
}

1 gerstgraser - Ingenieurbüro für Renaturierung, An der Pastoa 13, D-03042 Cottbus, Germany, phone:

${ }^{2}$ Institute for Risk and Disaster Reduction, University College London, Gower Street, WC1E 6BT London, United Kingdom, phone: +442076794466, e-mail: gianluca.pescaroli.14@ucl.ac.uk

\section{Abstract}

The adoption of the European Floods Directive (2007/60/EC) represented a crucial improvement

11 in the management of watercourses and coastlines. However, the beginning of a new phase of implementation requires the assessment of which emerging topics may be included in the review process. The aim of our research is to understand the existence of any legislative gaps that could limit the preparedness to cascading events and critical infrastructures breakdowns. First, we provide

15 a review of the Floods Directive, the cascading phenomena and the vulnerability of critical 16 infrastructures in the European legislation. Secondly, we analyse some case-studies to test the 17 present approach and to improve the work of decision makers. Our results suggest that the Floods 18 Directive tends to focus on localized flood impacts at smaller time scale and it could be ineffective to address the cross-scale impact of cascading events. Although some of the corrective actions may not be of competence of the Directive, we argue that their inclusion could limit uncertainties in the attribution of responsibilities and the coordination among different institutional levels.

\section{Keywords}

24 Cascading Effect, Cascading Disasters, Critical Infrastructure, European Union, Floods Directive, 
It is now evident that human activities contributed to the alterations of climate and precipitations, fostering a possible increase of extreme events (Ashton et al. 2003, Kay et al. 2009, Petrow and Merz 2009). This is likely to produce a raise in the total amount of damages caused by disasters in the long-term (Schwarze and Wagner 2004, EC 2015). In particular, floods represent a challenge for mitigation and resilience strategies because their impact is strictly related to the anthropic pressures on the environment, such as for growing urbanization (Slowik 2015) or misuse of floodplains (Smith and Petley 2009). In 2013, flood damages were 90\% above their 2003-2012 annual averages and caused estimated losses for US\$ 53.2 billion (Guha-Sapir et al. 2015). The flood occurred in costliest event after the ones in China (May-August 2010) and in Thailand in 2011 (Guha-Sapir et al. 2015). Only looking at the last decades, Europe suffered a series of other critical floods, including the events in Italy, France and Swiss Alps in 2000 (Gabella and Mantonvani 2001), along the Danube and the Elbe in 2002 (Ulbrich et al. 2003a, 2003b, Schwarze and Wagner 2004, Kreibich and Thieken 2009) and in the United Kingdom in 2007 (Pitt 2008, Bosher et al. 2009). (Uitenboogaart et al. 2009). non-structural mitigation measures and the use of advanced spatial planning instruments (Klijin et 
53 European Commission has been the adoption, in 2007, of the Directive on the Assessment and 54 Management of Flood Risk, 2007/60/EC (EU 2007), hereafter called Floods Directive, FD. Its principal aim is the reduction of flood risk consequences on human health, environment, cultural heritage and economic activities. Each EU Member State has to implement the FD at national and international level, including in this process a series of compulsory goals with fixed deadlines and the management of transboundary waterbodies (Müller 2013, Nones 2015). However, the possible consequences of cascading effects are only marginally described in the documentation, leaving a grey area that could limit the effective coordination of complex events.

Our hypothesis is that the implementation process of the FD should include a clear agenda on cascading effects at cross-spatial and cross-temporal scales, in order to cover the gaps in legislation and support other EU Directives. The approach is tested with a review of the state-of-the-art, coupled with an in-depth analysis of a few case studies. First, we explain the relevance of cascades, their linkages with critical infrastructures $(\mathrm{CI})$ and the possible influence of climate change patterns. Secondly, we describe the FD, its main goals and a list of consequences of flooding. The discussion considers both the open matters of interoperability and the overlapping competences with other EU directives, such as the INSPIRE Directive (EC 2007). The analysis of case studies explains an integrated approach based on sustainable rivers management and vulnerability reduction strategies that could be effective in flood-triggered cascades. Our conclusions suggest some consistent measures for water authorities and open fields of research for scholars, recommending not only discussion, but also the implementation of timely actions. primary threat is followed by a dynamic sequence of secondary hazards, evolving from a first trigger into a branching tree structure (May 2007). As example, earthquakes or floods can heavily damage roads, but also compromise electric grids, underground water supply and gas pipelines. The 
79 joint effect of natural triggers and damages to the infrastructures can generate fires, increasing the

80 difficulties in fighting them because of lack of water supply and inaccessible roads (Little 2002). In

81 other words, cascading events can be related to the disruption of CI, intended as those places where

82 physical attributes and functional nodes are accumulated (Alexander 2013). Despite the idea that

83 cascading is rare, recent studies showed that they are very common, with most triggers originating

84 from sectors such as energy, telecommunication/internet and transportation (Luiijf et al. 2009,

85 Bochkov et al. 2015). Together with the loss of services, the effect floods on CI is frequently 86 associated with 'NaTech' disasters (Natural events triggering Technological Disasters), when 87 vulnerable equipments such as high capacity tanks or pipelines contaminate water and pollute the 88 environment (Shaluf 2007, Cozzani et al. 2010, Krausmann et al. 2011).

89 Recently, Pescaroli and Alexander (2015) argued that cascading is distinguished by the existence 90 of unforeseen and non-linear progresses of subsidiary events, which spread towards the 91 vulnerabilities of society and the disruption of CI. Disasters escalate as time progresses, instead of 92 being stabilized by the full mobilization of emergency resources. In Figure 1 are reported the 93 differences between linear cause-effects relation and cascading, where 'the chain of interactions can 94 amplify an impact as it progresses thorough different states' (Pescaroli and Alexander 2015).

95

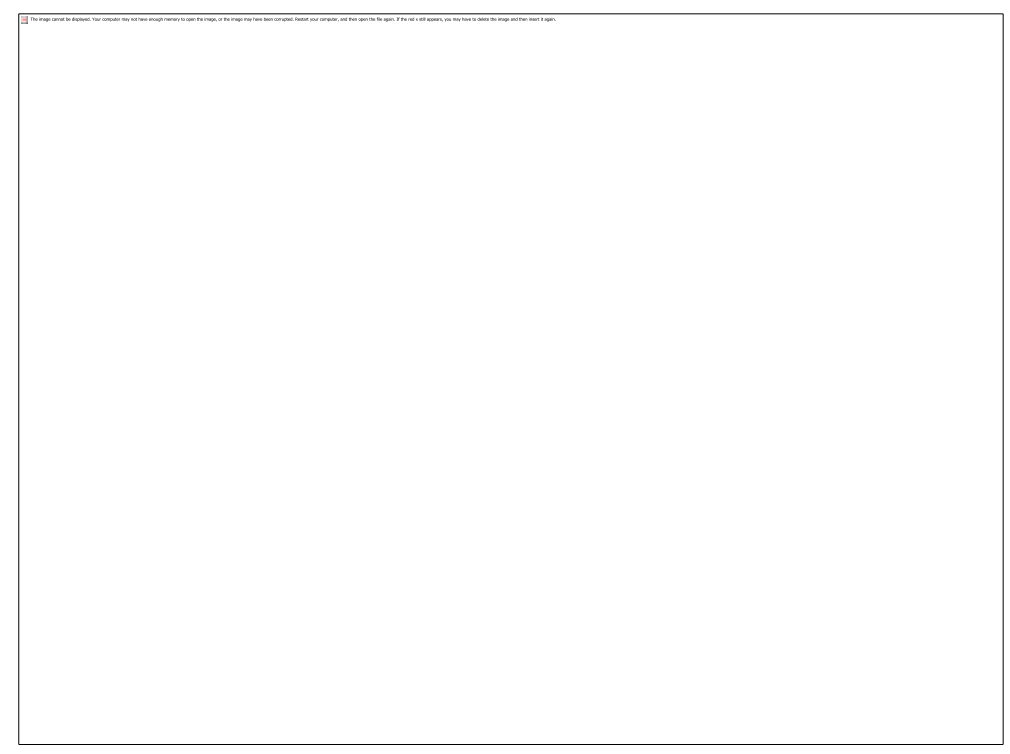

97 Figure 1. (a) Linear path of events in disasters, and (b) non-linear path of cascading, including 

cascading. II.

amplification and subsidiary disasters (adapted from Pescaroli and Alexander 2015).

It must be noted that this sequence tends to be more complex than in the past. The interdependency of the global system combined multi-level networks that are very sensible to changes, and even small perturbations can generate large-scale or cross-boundary damages (Helbing 2013). This has been evident since the early 2000s in different episodes, where CI disruptions caused widespread social breakdowns, such as the one caused by Hurricane Katrina in 2005 (Boin and McConnell 2007). In some cases, the main impact of cascades can be associated with secondary events: for example, the impact of 2011 Tōhoku earthquake was overwhelmed by the tsunami and the Fukushima meltdown, while the 2010 eruption of Eyjafjallajökull is not known for the damages of its lava but for being the cause of the widest disruption of air transportation since the World War

Institutional and political challenges are still open in most of the possible scenarios involving climate change. At the European level, the consequences of extreme climate change have been identified as critical adaptation challenges for the possible disruption of CI and their implied secondary effects on society (EC 2013a). When ecological changes propagate into societal crises, the response capacity can be affected by the fast spreading of secondary effects, fragmented information, communication failures, or difficulties in assigning responsibilities (Galaz et al. 2011). 

provides the background for concerted action at international level. This Directive aims to reduce risks and adverse consequences of flooding events. It has been implemented by Member States in three consecutive stages: a Preliminary Flood Risk Assessment completed in 2011, the development of Flood Hazard and Risk Maps for flood prone zones produced in 2013 and the creation of Flood Risk Management Plans concluded at the end of 2015. The law is intended to handle some key strategic issues: i) floods are natural phenomena that cannot be prevented and have the potential to cause displacements of people and fatalities, environmental and economical damages; ii) anthropogenic activities and climate change can contribute to increase likelihood and adverse consequences of floods; iii) measures to reduce flood risks within international river basins should be coordinated on a transnational level; iv) measures related to water and land use changes should be verified for their impacts on the flood risk (Müller 2013, Nones 2015). Following the EU guidance (EEA 2013), a list of possible flood consequences has been created, describing each type of event and their negative effects (Table 1). This approach has been integrated in the Flood Risk Management Plans in accordance with Articles 4, 5 and 13(1) of the FD, but many differences exist in its implementation among Member States. On the one hand, in many cases it was not feasible to report all the possible consequences of flooding. On the other hand, some countries reported on the Flood Risk Maps information that may increase the flood damage (Excimap 2007a, Nones 2015), such as storage of chemicals, vital networks and services (e.g., transportation, healthcare, water supply), impact of sediments.

Table 1. List of the types of consequences (adapted from EAA 2013).

\begin{tabular}{c|c}
\hline \multicolumn{1}{c|}{ Type of consequences } & subtype of consequences / description \\
\hline Human Health & Human Health: adverse consequences to human health, either as \\
\hline
\end{tabular}




\begin{tabular}{|c|c|}
\hline (Social) & $\begin{array}{l}\text { immediate or consequential impacts, such as might arise from } \\
\text { pollution, interruption of services related to water supply and } \\
\text { treatment, fatalities. } \\
\text { Community: adverse consequences to the community, such as } \\
\text { detrimental impacts on local governance and public administration, } \\
\text { emergency response, education, health and social work facilities. }\end{array}$ \\
\hline Environment & $\begin{array}{l}\text { Waterbodies status: adverse permanent or long-term consequences } \\
\text { on ecological or chemical status of surface water bodies or chemical } \\
\text { status of ground waterbodies affected, as concern under the WFD } \\
\text { (EU, 2000). Such consequences may arise from pollution (point and } \\
\text { diffuse) or due to hydromorphological impacts of flooding. } \\
\text { Protected Areas: adverse permanent or long-term consequences to } \\
\text { protected areas or waterbodies such as those designated under the } \\
\text { Birds and Habitats Directives (EU, 1992), bathing waters or } \\
\text { drinking water abstraction points. } \\
\text { Pollution Sources: sources of potential pollution during floods, } \\
\text { such as IPPC and Seveso installations, or point or diffuse sources. } \\
\text { Other: potential permanent or long-term adverse environmental } \\
\text { impacts. }\end{array}$ \\
\hline Cultural Heritage & $\begin{array}{l}\text { Cultural Assets: adverse permanent or long-term consequences to } \\
\text { cultural heritage. } \\
\text { Landscape: adverse permanent or long-term consequences on } \\
\text { cultural landscapes, which are cultural properties that represents the } \\
\text { combined works of nature and man. }\end{array}$ \\
\hline Economic & Property: adverse consequences to properties. \\
\hline
\end{tabular}


Infrastructure: adverse consequences to infrastructural assets.

Rural Land Use: adverse consequences to uses of the land.

Economic Activity: adverse consequences to sectors of economic activities.

Klijn et al. (2008) examined the evolution of flood risk management in England, France, but they also pointed out that 'a risk based approach for both analysis and management is seldom explicitly applied' (Klijn et al. 2008). Similarly, Evers and Nyberg (2013) argued that water management and land use planning are often distinct issues for decision makers, leading to different planning strategies and overlapping of jurisdictions. Following It is evident that a better consistency between procedure targets and long-term policies is needed, with the aim to improve the synergies between the FD and other European legislation, such as the European Water Framework Directive (WFD, EU 2000), the European Habitats Directive (HD, EC 1992) and the Infrastructure for Spatial Information in the European Community Directive (INSPIRE, EC 2007). One of the central steps in this process could be to apply in the FD a new definition of flooding consequences, which could incorporate also the vulnerability to large-scale events associated with cascading dynamics.

\subsection{CI as cross-cutting topic for the European Union}

162 The inclusion of the cascading concept in the FD implementation strategies should consider the overlapping competences and documentation about CI. The first European framework to analyse is the European Programme on Critical Infrastructure Protection (EPCIP), developed since 2006 (EC 2006). The early documentation ascribed the priority task to tackle terrorism, and adopted an 'all hazard approach' that did not mentioned explicitly floods. At that time, Member States were encouraged to identify national CI according to quantitative and qualitative effects of possible 
disruptions, including scopes, severities, health consequences, effects on environment and society.

169 However, the adoption of any assessment criteria was not perceived in an immediate timeframe.

170 Only the Directive on European Critical Infrastructures (EC 2008), in 2008, established a common 171 procedure for identifying European Critical Infrastructures (ECI) and for improving the protection 172 of strategic assets. At that time, the foci of the Directive were the energy and transportation sectors, 173 but it was recommended to promote a review with the inclusion of possible impacts on sectors such 174 as communication. In 2013 the Commission (EC 2013b) provided a practical implementation of the 175 EPCIP, with the inclusion of cross-sectors interdependencies, but the roadmap referred just to the Directorates General of Mobility and Transport (DG MOVE), Enterprise and Industry (DG GROW), Research and Innovation (R\&I), Energy (DG ENER), Humanitarian Aid and Civil 178 Protection (DG ECHO). For the first time, floods were mentioned explicitly as disruptive natural 179 events that could affect the European Gas Transmission Network, but their role was still marginal. 180 The report did not mention the possibility to have any integration with the FD.

181 Instead, the impact of floods on CI has been included in the Commission document on adaptation 182 to climate change (EC 2013a). In this case, it is suggested to integrate the approach of the FD with 183 changing flood patterns and intensity. It is argued that the last outcomes in climate change research 184 and hydrological scenarios could be updated in maps and plans every six years, improving the 185 overall accountability and reliability of information. Unfortunately, despite of a great effort in the FD implementation, official maps that indicate both potential damages and CI are still rare (Excimap 2007b). This problem can be referred to the high details of topographic data and the scarce availability of socio-economic indicators in many river basins (Tsakiris et al. 2009). 189 Similarly, in multi-level planning, the possible role of CI remains mostly associated with the direct 190 effects of disruptions (e.g., loss of lifelines and services), but they can cause also indirect effects, 191 such as the contamination generated by chemical leaks (Alexander 2013). It is recognized that, 192 NaTech risk maps that include the loss of CI are generally unavailable, or they just overlay natural 193 and technological hazards without contextualizing them (De Groeve et al. 2013). Even when natural 
hazards and CI are approached together in metadata, as happens in the case of the INSPIRE Directive (EU 2007), their qualitative assessment remains vague and almost undefined. According to Hickford et al. (2015), the use of fixed assumptions in planning failed to include cross-sectors interdependencies and long-term socio-economic challenges, mainly due to methodological limitations that did not include the co-evolution of socio-economic and technical systems. Thus, if cascading concept is applied in terms of non-linear escalation process, the need for horizontal actions becomes a priority.

\section{Case studies analysis}

Over the last years, several projects were promoted across Europe to assess the effects of flooding events at different temporal and spatial scales, setting a new range of mitigation measures. Growing attention was attributed to financing the analysis of emerging hazards and proposing new preparedness scenarios. This paper is the result of an interdisciplinary dialogue between researchers of two different projects financed by the European Commission, namely the HYTECH project on the WFD-FD analysis (http://hytech.dii.unipd.it), and the FORTRESS project on the cascading events (http://fortress-project.eu). We present a few case studies on the cascading effects of flooding events to understand and assess the non-linear consequences on economy, society and environment. The selection process was oriented by the emerging nature of the cascading topic, which implied a scarce availability of data. We had to refer mostly to case studies analysed in our projects, individual researches or evidences approached during some collateral scenarios building. In other words, more than providing an exhaustive comparison with well-structures evidences, our goal is to provide a basis for new studies. In line with the methodological approach suggested by

King et al. (1994), we adopted ex-ante some criteria to allow homogeneity of selection and future replicability: 
- cases had to be distinguished by cascading patterns, in line with the definition given by Pescaroli

219 and Alexander (2015). In particular, the presence of non-linear escalation dynamics had to be 220 evident in socio-ecological systems;

221 - cases had to provide a comprehensive view on natural and built environments, and social 222 vulnerabilities. They had to show the presence of anthropic vulnerabilities, which are only partially 223 addressed by the current form of the FD;

224 - cases had to be related to surface water environments, in particular rivers, which is the application 225 field of the FD analysed in the present paper.

\subsection{Venice Lagoon and Spree River: environment, ecology and hydromorphology}

Floods can be considered as a mass transfer of freshwater, sediments and contaminants along rivers. For this reason, the discharge increase is generally associated with a raise in the concentration of suspended matter, such as sediments and pollutants mobilized from the river bed or 231 floodplains.

232 In Venice Lagoon (Italy), the main source of contaminants is represented by small tributaries 233 flowing from the nearest farmlands. Therefore, control and reduce the related load is an essential 234 task for the safeguarding of the lagoon and its fragile environment (Zonta et al. 2005). Flooding 235 events in the inland streams can increase the concentration of heavy metals and anthropogenic 236 nutrients along the marshes, threatening the lagoon as a whole. In other words, the shift in the 237 balance produced by contaminants can generate effects on all the adaptation process, modifying 238 social, economical and political behaviours and producing dynamic feedbacks loops on ecosystems 239 (Holling 2001). Even if these delayed effects of floods are not considered in the Flood Risk 240 Management Plans, they are central carriers of complex crisis. According to Galaz et al. (2011), 241 non-liner biophysical changes can recombine potential ecological crisis with socio-economic and 242 political drivers to trigger cross-boundary and cross-sector cascades. 
During the FD implementation it is necessary to consider ecological, hydromorphological and 244 chemico-physical quality elements, in order to address the synergic effects with the WFD. Indeed, an increase of water discharge causes a mobilization of sediments, changing the morphology and altering the local habitat. The variation produced by local floods can alter rivers, derailing restoration projects with environmental and economical losses at watershed scale, as observed in a small restored reach of the Spree River in Germany (Nones and Gerstgraser 2016). In general, it must be noted that river restoration projects were built according to models that did not consider major floods with long return time periods (100-200 years), and did not take into account the slow morphological response to flow changes. In most cases no indications about the delayed impact of flooding events are reported in the Flood Risk Management Plans that cover restored reaches.

Similarly, floods in mountain regions involve a series of cross-scale consequences and effects, which must be included in the Flood Risk Management Plans together with the possible paths that generate them. For example, they can trigger landslides and debris flows (consequence on the environment), which can cause fatalities and displacement of inhabitants (social consequences), as well as damages on infrastructures, properties, agriculture and industries (economic impact). However, the evidence can be also counter-intuitive. Gill and Malamud (2014) recorded the interactions-relationships between over twenty natural hazards, drawn from six risk groups: geophysical, hydrological, shallow earth, atmospheric, biophysical and space hazards. They suggested that floods are very likely to be generated by primary triggers such as adverse meteorological conditions or earthquakes, more than be just the cause of cascading. This approach can be integrated with climate change scenarios to understand the long-term sensibility of areas to 264 combined risk, but also with better vulnerability assessments strategies that could address the roots 265 of secondary events, when they lie in anthropic causes (Pescaroli and Alexander 2015).

266 The following case studies will explain better this approach, focusing on social and economical systems. 
270 In summer 2002, heavy rainfalls led to extreme floods in the Elbe and Danube basins (Ulbrich et 271 al. 2003a, DKKV 2004, EEA 2010). More than twenty people were killed and substantial parts of 272 infrastructures were destroyed in Germany, with huge costs for public administration and private 273 citizens (Kreibich and Thieken 2009). The return period of this event was estimated to be around 274150 years, with a peak discharge of $4580 \mathrm{~m}^{3} / \mathrm{s}$ (Kreibich and Thieken 2009).

275 At that time, Dresden was the most affected area with significant losses of residential buildings, 276 industries, cultural and historic sites. The city is located on the Elbe River (Fig. 2) and has one of 277 the highest Social Vulnerability Index of Germany (Fekete 2009). 


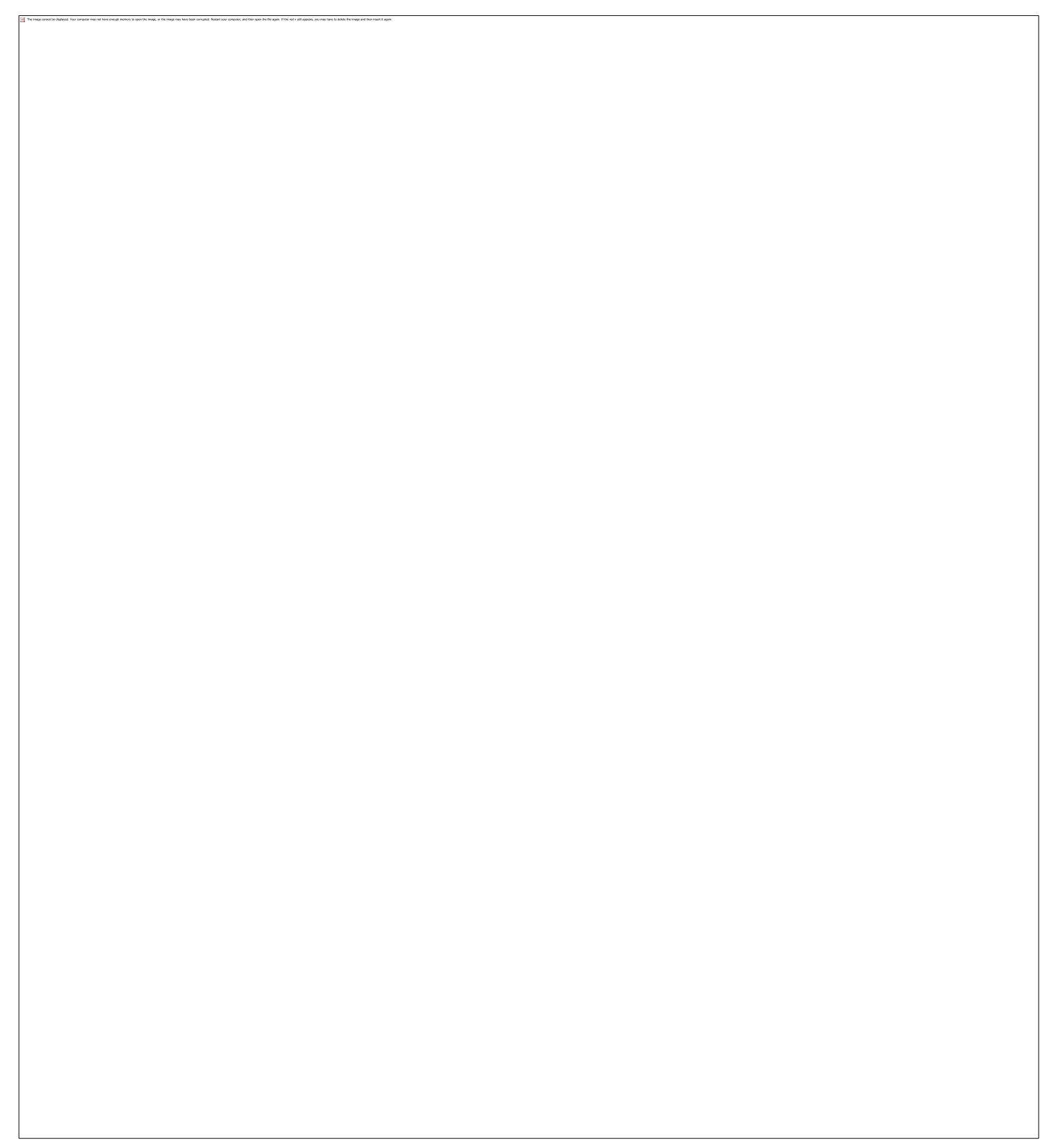

280 Figure 2. Map of Germany: location of Dresden and the Elbe basin.

282 Although Dresden has a long flood history, the risk awareness of the community faded after the 283 last strong events occurred in 1940s. Following the German reunification, the lack of space and the 284 low home ownership rate induced the local authorities to establish new settlement areas within the 285 Elbe floodplain (Fig. 3a). Strong complains were made without significant results by numerous 286 environmental agencies (Kreibich and Thieken 2009). Consequently, more than $50 \%$ of the 2002 287 flooded area was occupied by settlements, as visible from Figure 3b, and this caused several 288 consequences on citizens and economic activities (EEA 2010). 

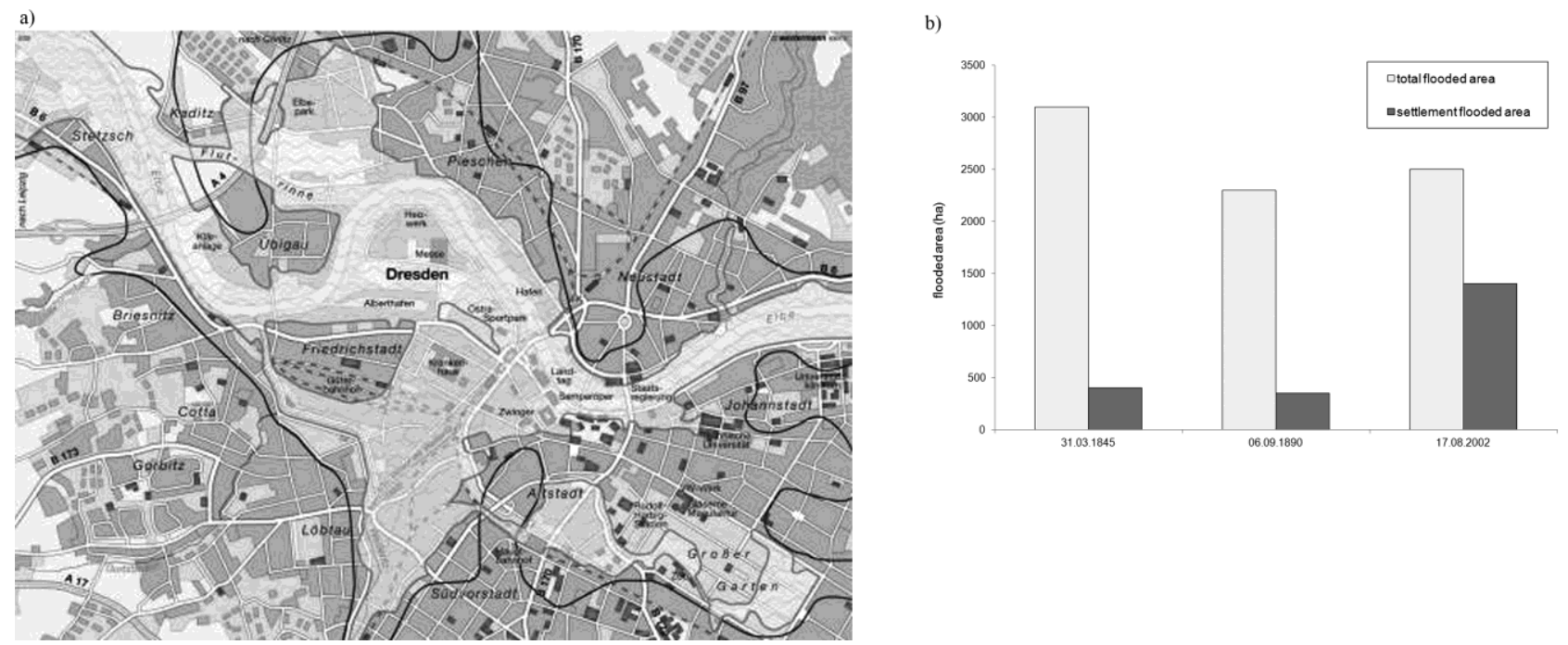

Figure 3. a) Central areas of Dresden flooded in 2002. b) Comparison between total and settlement areas flooded in Dresden during three events (source European Environment Agency 2010).

Together with environmental and social problems, this event had an important economic impact, which was not forecasted in the flooding plans. In the short-term, it caused the collapse of local industries and facilities, or, at least, forced them to stop their operations. In the medium term, the reconstruction supported the regional growth, new employment and the increase of the consumers spending tendency, but problems were observed at long-term. For example, a real growth of around $2991 \%$ was measured for eastern Germany since 2003, as a short-term result of the flood-related recovery programmes (Schwarze and Wagner 2004). On the one hand, this positive effect of rebuilding was associated with an overestimation of the immediate effects, but also to a projected increase in spending trend in the flooded regions, which was largely offset by losses in turnover and demand outside the affected areas. On the other hand, because of the limited regional growth effect,

304 the overall long-term impact of floods in Germany became negative, causing a decrease of the consumer confidence and spending as a reaction to the governmental fiscal policies. The diminished credibility of these new economic policies can be considered another cascading consequence of a flooding event. 


\subsection{United Kingdom and Parma: vulnerability of Critical Infrastructure}

310 In the summer of 2007, the United Kingdom was affected by various episodes of flooding. The

311 official report of these events, developed by Sir Michael Pitt (2008), described what happened as 312 'the biggest civil emergency in British history'. More than 55000 properties were inundated and 313 around 7000 citizens were rescued by emergency services, and floods were associated with the 314 'largest loss of essential services since World War II' (Pitt 2008). Three key episodes in 315 Gloucestershire pointed out the vulnerability of society to the disruption of CI: first, the loss of 316 Mythe water treatment works left 350000 people without water supply for up to 17 days. Secondly, 317 a major electricity substation in Castle Meads had to be turned off and left further 42000 citizens 318 without electricity for one day. Finally, transport network failed and around 10000 commuters were 319 trapped on the motorway. In other words, the challenges posed by these flooding events cannot be 320 viewed in isolation as they are shared across the entire system and its organizational structure (Pitt 321 2008). Only the cooperation between military and civil emergency services prevented the water 322 from reaching another electricity substation that served half a million residents. Field crops were 323 lost with damages estimated of around $£ 220$ million, while further costs were incurred in damages 324 to roads and complementary infrastructures for a total of $£ 5$ billion (Smith and Petley 2009). ). In 325 other words, the 2007 floods challenged the entire system and its organizational structure (Pitt 326 2008). The UK Cabinet Office (2011) used this event to explain how a single localized event could 327 generate 'far reaching implications'. According to this document, cascading effects have been 328 associated with the unexpected path of emergency, which escalated with the progressive 329 involvement of CI and their disruption. Physical dependencies and interdependencies resulted from 330 functional connection among sites as, for example, water treatment plants that needed electricity to 331 work, while geographical dependencies were associated with the collocation in the same area of 332 critical nodes of service (Figure 4). 


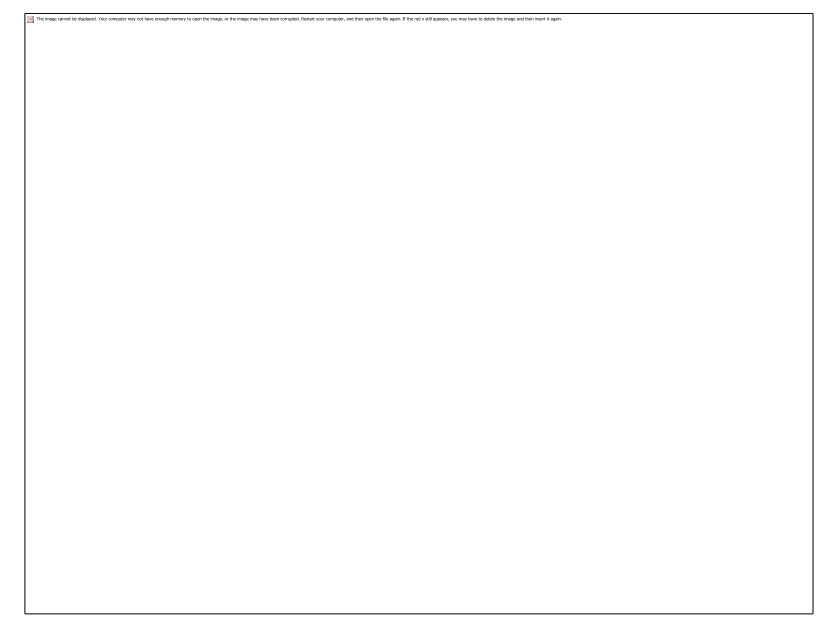

335 Figure 4. Geographical dependencies in 2007 summer floods (source: UK Cabinet Office 2011).

The experience of 2007 floods, together with the 2010 eruption of Eyjafjallajökull and other extreme events, lead the UK Government to improve the guidelines for infrastructure resilience 339 (UK Cabinet Office 2010). Similarly, the Pitt Review (2008) originated the Flood Water 340 Management Act of 2010, which interacts with the Flood Risk Regulations of 2009, transposing the 341 FD into the UK system. Their synergies are used to understand risks and impacts of natural hazards, 342 but also to point out the vulnerability of CI and the challenges represented by a possible loss of 343 services (UK Cabinet Office 2010, 2011).

344 A coherent approach to this topic seems to be rare among the members of the European Union, 345 together with a lack of shared procedures on the assessment of the social consequences of floods as 346 required by the FD (Tsakiris et al. 2009). The integration of cascading concept in the FD should 347 lead to produce more homogeneous data where hubs and nodes of vital services are located, how 348 many citizens could be affected by their total or partial disruption, and in which terms this would 349 happen. This may lead to produce joint contingency plans and share better information between 350 private and public actors at local, regional and national level that could produce better information 351 for citizens. Instead, until now most attention has been concentrated on those CI that represent 352 unequivocal technological hazards (e.g. chemicals plants), or have a well-known strategic value 353 (e.g. airports). 
The flooding event happened in Parma (Italy) in October 2014 is a clear and recent example of 355 how the FD has some consistent gaps on cascading. The city is a well-known centre of food excellence in Northern Italy and is located in a region that, for many years, has been considered a model for participatory democracy (Putnam et al. 1994). All the area presents a strong process of urbanization and soil consumption that is likely to increase its vulnerability in the long-term. However, the FD was effectively integrated in the national legislation and both Hazard and Risk 360 Maps were implemented at all levels (Regione Emilia-Romagna 2014). In 2014, between October 36110 and October 13, a concentration of adverse meteorological conditions caused heavy rainfalls and landslides in the mountain district. Parma, which is located in the valley on the confluence between the Parma River and the Baganza Stream, had three districts partially flooded, with substantial economic damages but no life losses. According to the official data by the regional Civil Protection 365 (2015), evacuation was needed for 14 citizens and a total of 96 patients of a hospital and a nursing home located near the river. However, 'the severity of impact was increased by the total interruption of both telephone and mobile coverage supplied by the provider Telecom in the districts of Piacenza, Parma, Reggio Emilia and Modena for the flooding of the Telecom hub 369 located in the Po street. This disruption caused a series of communication problems to the whole community' (Civil Protection Emilia-Romagna 2015). In other words, even if the geographical space that was flooded was somehow limited, the involvement of a single building disrupted the communications for the western portion of the Emilia-Romagna Region for days. Immediately after this event, the authorities improved the Risk Maps and proposed a series of new mitigation measures, with updated versions available in just two months (Autorità di Bacino del Fiume Po 2015). However, in line with the FD, they still included just CI representing technological hazards, such as chemicals industries and wastewater treatments plants. The approach adopted was limited to overlap different layers, more than understanding the vulnerabilities of space, in line with the cases analysed by De Groeve et al. (2013). The other dimension of interdependencies and cross-scale 
interactions proposed in the EPCIP were still missing, suggesting the need for a direct integration of this topic in the FD.

\section{Conclusions}

The review of the state-of-the-art and the analysis of the case studies verified our hypothesis: despite significative efforts to improve the FD, open challenges remain associated with cascading events. The joint assessment of flooding events and CI vulnerability seems far to be included together in a homogeneous process. Our review suggests the existence of three priority areas to address: i) scientific limitations can generate high uncertainty or non-availability of data on the long-term impact of events, in particular when social damages are involved; ii) spatial scales can be difficult to determine if the trigger hazard causes the disruption of highly interconnected infrastructures, such as communication hubs, transportation nodes or strategic lines of energy supply; iii) cascading requires the acceptance of possible reasonable worst case scenarios, which probability sometimes is simply underestimated by policy makers or public and private managers.

393 In first instance, the FD should include a higher balance between hazard and vulnerability management to provide some better advice to water managers. This problem was already reflected in a scarce tendency to implement non structural mitigation measures (Klijn et al. 2008), but the adoption of a perspective on cascading events suggests further attention on the matter. If cascades are distinguished by the non-linear escalation process in anthropogenic systems (Pescaroli and 398 Alexander 2015) and, in the case of ecological crisis, they can recombine with human stressors 399 (Galaz et al. 2011), a focus on 'risk' and 'impact' may be not enough. Instead, Flood Risk 400 Management Plans could integrate the impact of flooding events at larger spatial and temporal 401 scales. In other words, it must be considered that disasters are generated inside the society and 402 sometimes their causes have quite remote roots in the social, economical and political process 403 (Wisner et. al. 2003). This approach points out the need of a better integration of common standards 404 for vulnerability assessment process in the FD implementation, as well as an in-depth analysis of 
existing synergies with other EU Directives. Firstly, a priority should be attributed to support maps 406 and rankings that include CI interdependencies. Secondly, Risk Management Plans should codify 407 and consider the incidence of the sensible population (e.g. disabled or aged citizens) and community 408 based stressors that could amplify the impact of the crisis. Finally, there should be highlighted the 409 existence of main economic drivers and environmental features that could generate long-term chain 410 effects in case of interruption.

411 Clearly, the paper represents only a first attempt to apply the concept of cascading effects to the 412 current European legislation and do not pretend to be exhaustive. Some limitations of our work 413 exist and are explained along the text, but they seem not to invalidate the proposed approach. 414 Instead, they may be used to suggest open fields of research. First, we recognize that we have been 415 limited by the lack of structured databases that could allow the comparison of our case studies with 416 other evidences. This gap could represent an opportunity for scholars that are interested in more 417 systematic analyses of the topic, testing or improving the small evidences we provided. The criteria 418 we adopted allow more in-depth analyses, leaving open possibilities for improving the sistematicity 419 of our results. Moreover, further research is needed to define how and in which form a better 420 understanding of social vulnerabilities can help to improve the long-term implementation of 421 mitigation measures and preparedness practices. This point suggests to work for a better translation 422 of cascading in terms of economic and functional impacts, in particular under worst climate change 423 scenarios. Reforms to the management of river basins and floodplains are just one part of the 424 possible steps required in that direction.

\section{Acknowledgments}

427 The work performed by Michael Nones was supported by the Research Executive Agency, 428 through the $7^{\text {th }}$ Framework Programme of the European Union, Support for Training and Career 429 Development of Researchers (Marie Curie - FP7-PEOPLE-2012-ITN), which funded the Initial 
Training Network (ITN) HYTECH 'Hydrodynamic Transport in Ecologically Critical

431 Heterogeneous Interfaces', N. 316546.

432 The work of Gianluca Pescaroli has been carried out under the aegis of the EC FP7 FORTRESS 433 project. FORTRESS is funded by the European Commission within FP7- Area 10.4.1 434 'Preparedness, prevention, mitigation and planning', TOPIC SEC-2013.4.1-2, SEC-2013.2.1435 2, Grant 607579.

436 The authors acknowledge the Editor and the two anonymous reviewers for their precious comments 437 and feedbacks.

\section{References}

440 Alexander, D.E., 2013. Critical Infrastructure. In Penuel K.B., Statler M. and Hagen R. (Eds.), 441 Encyclopedia of Crisis Management, Sage, Thousand Oaks, California, 208-211.

442 Ashton, V., Aziz, H., Keith, S., and Smith, T., 2003. Review of EU Flood R\&D Projects. Report 443 prepared as a part of the group management project on the M.Sc. Water Resources Technology 444 and Management Course, University of Birmingham, Department of Civil Engineering, 445 Birmingham.

446 Autorità di Bacino del Fiume Po, 2015. Progetto di Piano per la valutazione e la gestione del 447 rischio di alluvioni: Mappatura della pericolosità e valutazione dei rischi. Parma, 22 December 448 2014, http://www.adbpo.it [Accessed 14 July 2015]. in Italian.

449 Bochkov, A., Lesnykh, V., Zhigirev, N., and lavrukhin, Y., 2015. Some methodical aspects of 450 critical infrastructure protection. Safety Science, 79, 229-242.

451 Bosher, L., Dainty, A., Carrillo, P., Glass, J., and Price, A., 2009. Attaining improved resilience to 452 floods: a proactive multi-stakeholder approach. Disaster Prevention and Management: An 453 International Journal, 18 (1), 9-22. 
Boin, A., and Mc Connell, A., 2007. Preparing for Critical Infrastructure Breakdowns: the limits of 455 Crisis Management and the Need for Resilience. Journal of Contingencies and Crisis Management, 15 (1), 50-59.

Civil Protection Emilia-Romagna, 2015. Piano dei primi interventi urgenti di Protezione Civile in conseguenza delle eccezionali avversità atmosferiche che nei giorni 13 e 14 ottobre hanno colpito il territorio delle province di Parma e Piacenza. Bologna, OCDPC 202, 14/11/2014, http://www.servizi.regione.emilia-romagna.it [Accessed 14 July 2015]. in Italian.

461 Cozzani, V., Campedel, M., Renni, E., and Krausmann, E., 2010. Industrial accidents triggered by 462 flood events: Analysis of past accidents. Journal of Hazardous Materials, 175 (1), 501-509.

Cruz, A.M., Steinberg, L.J., Vetere Arellano A.L., Nordvik, J.P., and Pisano, F., 2004. State of the 464 Art in Natech Risk Management. EUR 21292 EN. European Communities, Brussels.

465 De Groeve, T., Annunziato, A., Vernaccini, L., Salamon, P., Thielen, J., San Miguel, J., Camia, 466 A., Vogt, J., Krausmann, E., Wood, M., Guagnini, E., Giannopoulos, G., Pursiainen, C., and 467 Gattinesi, P., 2013. Overview of Disaster Risks that the EU faces. European Commission, JRC 468 Scientific and Policy Reports. Joint Research Centre, Ispra.

469 DKKV, 2004. Flood Risk Reduction in Germany: Lessons Learned from the 2002 Disaster in the 470 Elbe Region. DKKV Publication 29e.

471 EC, European Commission, 1992. Council Directive 92/43/EEC of 21 May 1992 on the conservation of natural habitats and of wild fauna and flora. Official Journal L 206.

EC, European Commission, 2006. Communication from the Commission on the Creation on an 474 European Programme of Critical Infrastructure Protection. COM(2006) 786 final, European 475 Commission, Brussels.

476 EC, European Commission, 2007. Directive 2007/2/EC of The European Parliament and of the 477 Council of 14 March 2007 establishing an Infrastructure for Spatial Information in the European 478 Community (INSPIRE). Official Journal L108/1. 
EC, European Commission, 2008. Council Directive of 8 December 2008 on the identification and designation of European critical infrastructure and the assessment of the need to improve their protection. 2008/114/EC, European Commission, Brussels.

EC, European Commission, 2013a. Commission staff working document - Adapting infrastructure to climate change. SWD(2013) 137 final, European Commission, Brussels.

EC, European Commission, 2013b. Commission staff working document on a new approach on the European Programme for critical infrastructure protection-Making European critical infrastructure more secure. SWD(2013) 318 final, European Commission, Brussels.

EC, European Commission, 2015. Communication from the Commission to the European Parliament and the Council - The Water Framework Directive and the Floods Directive: Actions towards the 'good status' of EU water and to reduce flood risks. $\operatorname{COM(2015)} 120$ final, European Commission, Brussels.

EEA, European Environment Agency, 2010. Flood plains of the river Elbe in the municipality of Dresden, Germany, during different flooding events. EEA Figure, Data and Maps, Copenhagen.

EEA, European Environment Agency, 2011. Mapping the impacts of natural hazards and technological accidents in Europe. EEA Technical report No. 13, Luxembourg.

EEA, European Environment Agency, 2013. Guidance for Reporting under the Floods Directive (2007/60/EC). Guidance Document No. 29, Luxembourg.

EU, European Union, 1992. Council Directive 92/43/EEC of 21 May 1992 on the conservation of natural habitats and of wild fauna and flora. Official Journal L206, 22.07.1992.

EU, European Union, 2000. Directive of the European Parliament and of the Council 2000/60/EC Establishing a Framework for Community Action in the Field of Water Policy. Official Journal C513, 23.10.2000.

EU, European Union, 2007. Directive 2007/60/EC of the European Parliament and of the Council of 23 October 2007 on the Assessment and the Management of Flood Risks. Official Journal L288, 6.11.2007. 
505 Evers, M., and Nyberg, L., 2013. Coherence and inconsistency of European instruments for 506 integrated river basin management. Int. Journal of River Basin Management, 11 (2), 139-152.

507 Excimap, 2007a. Handbook on good practices for flood mapping in Europe.

508 Excimap, 2007b. Atlas of Flood Maps: Example from 19 European countries, USA and Japan.

509 Fekete, A., 2009. Validation of a social vulnerability index in context to river-floods in Germany.

$510 \quad$ Natural Hazards and Earth System Science, 9 (2), 393-403.

511 Gabella, M., and Mantonvani, R., 2001. The floods of 13-16 October 2000 in Piedmont (Italy):

512 Quantitative precipitation estimates using radar and a network of gauges. Weather, 56 (10), 337$513 \quad 343$.

514 Galaz, V., Moberg, F., Olsson, E.K., Paglia, E., and Parker, C., 2011. Institutional and political 515 leadership dimensions of cascading ecological crisis. Public Administration, 89 (2), 361-380.

516 Gill, J.C., and Malamud, B.D., 2014. Reviewing and visualizing the interactions of natural hazards. $517 \quad$ Reviews of Geophysics, 52 (4), 1-43.

518 Guha-Sapir D., Hoyois, P., and Below, R., 2014. Annual Disaster Statistical Review 2013: The 519 Numbers and Trends. Centre for Research on the Epidemiology of Disasters (CRED), Université 520 Catholique de Louvain, Belgium.

521 Hedelin, B., 2015. The EU floods directive in Sweden: opportunities for integrated and 522 participatory flood risk planning. Journal of Flood Risk Management. doi: 10.1111/jfr3.12162

523 Helbing, D., 2013. Globally networked risks and how to respond. Nature, 497 (7447), 51-59.

524 Hickford, A.J., Nicholls, R.J., Otto, A., Hall, J.W., Blainey, S.P., Tran, M. and Baruah, P., 2015. 525 Creating an ensemble of future strategies for national infrastructure provision. Futures, 66, 13-24. 526 Holling, C.S., 2001. Understanding the Complexity of Economic, Ecological, and Social Systems. $527 \quad$ Ecosystems, 4 (5), 390-405.

528 Kay, A.L., Davies, H.N., Bell, V.A., and Jones, R.G., 2009. Comparison of uncertainty sources for 529 climate change impacts: flood frequency in England. Climatic Change, 92 (1-2), 41-63. 
530 King, G. Keohane, R., and Verba, S., 1994. Designing Social Inquiry. Princeton University Press, $531 \quad$ Princeton.

532 Klijn, F., Samuels, P., and Van Os, A., 2008. Towards flood risk management in the EU: state of 533 affairs with examples from various European countries. Int. Journal of River Basin Management, $534 \quad 6(4), 307-321$.

535 Kreibich, H., and Thieken, A.H., 2009. Coping with floods in the city of Dresden, Germany. $536 \quad$ Natural Hazards, 31 (3), 423-436.

537 Krausmann, E., Renni, E., Campedel, M., and Cozzani, V., 2011. Industrial accidents triggered by 538 earthquakes, floods and lightning: lessons learned from a database analysis. Natural Hazards, 59 $539 \quad(1), 285-300$

540 Little, R.G., 2002. Controlling cascading failure: understanding the vulnerabilities of interconnected 541 infrastructures, Journal of Urban Technology, 9 (1), 109-123.

542 Luiijf, E., Nieuwenhuijs, A., Klaver, M., Van Eeten, M., and Cruz, E., 2009. Empirical Findings on 543 Critical Infrastructure Dependencies in Europe. In Setola R. and Geretshuber S. (Eds.): CRITIS $544 \quad 2008$, LNCS 5508, 302-310.

545 May, F., 2007. Cascading Disaster Models in Postburn Flash Flood. In Butler, B.W., Cook, W., The 546 Fire Environment - Innovations, Management and Policy; Conference Proceedings. US 547 Department of Agriculture Forest Service, Washington, DC, 446-463.

548 McGee, S., Frittman, J., Ahn, S., and Murray, S., 2014. Risk Relationships and Cascading effects in 549 Critical Infrastructures: Implications for the Hyogo Framework. United Nations Office for 550 Disaster Risk Reduction, Global Assessment Report on Disaster Risk Reduction.

551 Mostert, E., and Junier, S.J., 2009. The European flood risk directive: challenges for research. $552 \quad$ Hydrology and Earth System Sciences Discussions, 6 (4), 4961-4988.

553 Müller, U., 2013. Implementation of the Flood Risk management Directive in Selected European 554 Countries. Int. Journal of Disaster Risk Science, 4 (3), 115-125. 
Nones, M., and Gerstgraser, C., 2016. Morphological changes of a restored reach: the case of the Spree River, Cottbus, Germany. Hydrodynamic and mass transport at freshwater aquatic interfaces, series GeoPlanet Earth and Planetary Sciences. eds. Springer International Publishing.

Nones, M., 2015. Implementation of the Floods Directive in selected EU Member States. Water and Environmental Journal, 29 (2), 412-418.

Pescaroli, G., and Alexander, D., 2015. A definition of cascading disaster and cascading effects: Going beyond the “toping dominos” metaphor. Planet@Risk, 2 (3), 1-4.

Petrow, T., and Merz, B., 2009. Trends in flood magnitude, frequency and seasonality in Germany in the period 1951-2002. Journal of Hydrology, 371 (1), 129-141.

Pitt, M., 2008. Learning Lessons from the 2007 Floods. Final Report. Cabinet Office, Whitehall, London.

Pursiainen, C., 2009. The Challenges for European Critical Infrastructure Protection. Journal of European Integration, 31(6), 721-739.

Putnam, R.D., Leonardi, R., and Nanetti, R.Y., 1994. Making Democracy Work: Civic Traditions in Modern Italy. Princeton University Press, Princeton, NJ, 280.

Regione Emilia-Romagna, 2014. La Direttiva Alluvioni 2007/60/CE e le attività in corso nel territorio della Regione Emilia Romagna. Regione Emilia Romagna, Bologna, http://ambiente.regione.emilia-romagna.it [Accessed 14 July 2015]. in Italian.

Schwarze, R., and Wagner, G.G., 2004. In the aftermath of Dresden: New directions in German flood insurance. The Geneva Papers on Risk and Insurance-Issues and Practice, 29 (2), 154-168.

Shaluf, I.M., 2007. An overview on the technological disasters. Disaster Prevention and Management, 16 (3), 380-390.

Slowik, M., 2015. Is history of rivers important in restoration projects? The example of human impact on a lowland river valley (the Obra River, Poland). Geomorphology 251, 50-63.

Smith, K., and Petley, D.N., 2009. Environmental Hazards. Routledge, London. 
580 Tsakiris, G., Nalbantis, I., and Pistrika, A., 2009. Critical Technical Issues on the EU Flood 581 Directive. European Water, 25 (26), 39-51.

582 UK Cabinet Office, 2010. Strategic Framework and Policy Statement on Improving the Resilience 583 of Critical Infrastructure to Disruption from Natural Hazards. Cabinet Office, Whitehall, London. 584 UK Cabinet Office, 2011. Keeping the Country Running: Natural Hazards and Infrastructure. 585 Cabinet Office, Whitehall, London.

586 Uitenboogaart, Y., van Kempen, J.J.H., Wiering, M.A., and van Rijswick, H.F.M.W., 2009. Dealing 587 with complexity and policy discretion: A comparison of the implementation process of the 588 European Water Framework Directive in five member states. Den Haag: SDU Uitgevers.

589 Ulbrich, U., Brücher, T., Fink, A.H., Leckebusch, G.C., Krüger, A., and Pinto, J.G., 2003a. The 590 central European floods of August 2002: Part 1 - Rainfall periods and flood development. $591 \quad$ Weather, $58(10), 371-377$.

592 Ulbrich, U., Brücher, T., Fink, A.H., Leckebusch, G.C., Krüger, A., and Pinto, J.G., 2003b. The 593 central European floods of August 2002: Part 2 - Synoptic causes and considerations with respect 594 to climatic change. Weather, 58 (11), 434-442.

595 Wisner, B., Blaikie, P., Cannon, T., and Davis, I. 2003. At Risk-Natural Hazards, people's 596 vulnerability and disasters. Routledge, New York.

597 Zonta, R., Collavini, F., Zaggia L., and Zuliani, A., 2005. The effect of floods on the transport of 598 suspended sediments and contaminants: A case study from the estuary of the Dese River (Venice 599 Lagoon, Italy. Environment International, 31 (7), 948-958. 